\title{
Relationship between Eating Disorder, Body Fat Percentage, and Physical Activity among Sarawak Female National Athletes
}

\author{
Patricia Pawa Pitil, Wan Juliana Emeih Wahed
}

\begin{abstract}
Purpose: This study aimed to examine the eating disorder and physical activity in relation to type of sports and body fat percentages among national female athletes in Sarawak (N=150).

Methodology: Eating Attitude Test (EAT-26) and Global Physical Activity Questionnaire (GPAQ) were employed to measure the eating disorders and physical activity. Anthropometric measurement and body composition (body fat percentage) were obtained.

Results: Majority of the athletes were at low risk of an eating disorder (91.4\%). Only a few indicated as high risk (8.6\%). Moderately active athletes explained higher eating disorders in dieting, bulimia nervosa and food preoccupation. The non-weight sports athletes also exhibited higher eating disorders compared to its counterpart. Younger athletes were at higher eating disorder, but age was not significant in the subscales measured; except for food preoccupation where it was prominent in age 16 to 18 years old. Oral control did not associate with all the independent variables. Some relationships observed between body fat percentage and eating disorder and the subscales.

Conclusion: There is a need for coaches' attention and intervention on these athletes to prevent abnormal eating behavior among the young female athletes. This study highlights interesting findings where the less active athletes and the non-weight sports category athletes exhibit higher eating disorders issues.
\end{abstract}

Keywords: Body Fat Percentage; Eating Disorder; Female Athletes; National Athletes; Physical Activity; Sarawak Athletes.

\section{INTRODUCTION}

Eating disorders are irrational behaviours that can consume a person's life to the point of becoming life-threatening ${ }^{1,2}$. They are illnesses that are characterized by irregular eating habits and concern too much on body weight or shape ${ }^{3}$, namely, anorexia nervosa, bulimia and binge eating. These are unhealthy attitudes towards food ${ }^{4}$ that could endanger life. Self-induced vomiting is one of the characteristics of the episode of bulimic sufferers, where they experience a binge-purge cycle with extreme overeating on

Revised Manuscript Received on September 22, 2019

Patricia Pawa Pitil, Lecturer, Faculty of Sports Science \& Recreation, Universiti Teknologi MARA, Cawangan Sarawak, Kampus Samarahan, Jalan Meranek, 94300, Kota Samarahan, Malaysia.patriciapawa@uitm.edu.my

Wan Juliana Emeih Wahed, Lecturer, Faculty of Art \& Design, Universiti Teknologi MARA, Cawangan Sarawak, Kampus Samarahan, Jalan Meranek, 94300, Kota Samarahan, Malaysia. non-nutritious high caloric food ${ }^{5}$.

Heavier body weight among girls makes them tend to restrict their food intake and felt unpleasant with their body image $^{6}$ due to worrying about body weight. Self-esteem and body image of the girls could be affected and thus, becoming the reason of a higher risk for unhealthy eating ${ }^{6}$. However, individuals who are absent of eating-related disorders had a lower BMI compared to individuals with eating disorders ${ }^{7}$. This could suggest that the bodyweight concern has taken the individual with excess body weight to use a shortcut of losing weight by practising eating disorder.

Physical, psychological and social changes occur substantially during adolescence year. Inadequate intake of nutrients would associate with delayed onset of puberty. The growth rate is dependent on sufficient nutrients intake by the adolescents. However, when being thin is widely perceived as being healthy, the fear of obesity is becoming rampant and it happens in most countries ${ }^{8}$. To athletes, some of them perceived that being thin is the indicator of $\mathrm{fit}^{3}$. Thus, in the struggle to look fit, these athletes are prone to practice abnormal eating behavior. As most studies reported that athletes were more likely to have an eating disorder if compare to the non-athletes, however, the factors that associated with the eating disorders among the female adolescents has not yet established. An early age commitment to sports might lead the athletes to this unhealthy eating behavior.

The rate of this unhealthy behavior are greater among adolescent and young women if compared to men ${ }^{9}$. In Malaysia, disordered eating among female adolescents is alarming ${ }^{10}$. The prevalence of obesity in Malaysian adolescents increased dramatically from $6.1 \%,{ }^{5}$ in 2011 to $11.9 \%{ }^{5}$ in 2015 . Those who aged 12 to 19 years old were $14.2 \%$ overweight and $10.1 \%$ were obese ${ }^{11}$.

To understand further the female adolescents specifically athletes in eating disorder susceptibility, there is a need to conduct a study focusing on this matter. To the best of knowledge, there is limited study focusing on the female adolescent athletes on eating behavior and its relationship with physical activity by their sports category and age groups. Since an eating disorder has shown to be started in adolescence, early identification is a must among the athletes. Thus, this study aimed to measure the relationship between eating disorder and body composition by physical activity, sports categories and

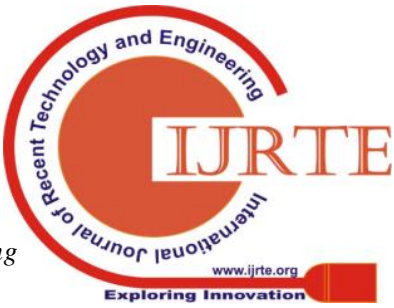


age groups among the female athletes of Sukan Malaysia (SUKMA) Sarawak.

\section{METHODOLOGY}

This study employed a cross-sectional design which focusing on national female athletes in Sarawak who competed for SUKMA aged 21 years old and below. The sample size for the study was calculated ${ }^{2}$ where the total female athletes' population who competed in SUKMA for Sarawak was 296. A final sample of $N=150$ participants was recruited using a convenience sampling technique with an added number to minimize the dropout rate. Approvals to conduct the study were obtained from the Research Management Unit of Universiti Teknologi MARA Kampus Samarahan, Sarawak and Sarawak Sports Corporation.

\section{A. Physical Activity}

The Global Physical Activity Questionnaire (GPAQ) ${ }^{12}$ was utilized to measure the pattern physical activity which has shown a high reliability and validity ${ }^{13}$. A person's overall energy expenditure was calculated based on the metabolic equivalent (MET) values. The total physical activity was expressed as MET-minutes/week = the sum of the total MET minutes of activity computed for each setting $^{12}$.

\section{B. Anthropometry Measurements}

The participants' height was measured using a body meter to the nearest $0.5 \mathrm{~cm}$ and the weight and the body fat percentage was obtained by using Karada Scan Body Composition Monitor Model HBF - 375 (OMRON). Each measurement was taken three times and the mean score was recorded. Weight was recorded to the nearest $0.1 \mathrm{~kg}$.

\section{Eating Disorder}

The eating disorder presence among the athletes was assessed by using The Eating Attitudes Test (EAT-26) and reported a high internal consistency, $\alpha=0.90^{14}$. It is comprised of 26 scales of three dimensions; dieting, bulimia and food preoccupation, and oral control ${ }^{15}$. A score greater than 20 has a risk of eating disorder.

\section{Data Analysis}

The data were analyzed by using the Statistical Package for Social Science (SPSS) version 22.0. Descriptive statistics for all variables were presented. The Pearson correlation test and Chi-square test was conducted to measure the relationship and association between the variables. An independent sample $\mathrm{t}$-test and one-way analysis of variance (ANOVA) were employed to compare the eating disorder between weight and non-weight category sports, age groups and physical activity. The statistical significant was set at .05 $(p<.05)$.

\section{ReSUlts}

As overall, the participants were categorized as very active (3034.91 \pm 2489.7 METs-min/week) (Table 1). Majority of the participants were moderately active (110 $(73.33 \%))$ and only $40(26.67 \%)$ were very active. There was zero percentage of a low physical activity reported. In comparing the eating disorder and the subscales by the physical activity, there were significant different observed (Table 3).

Mean eating disorder for moderately active (9.327 \pm 6.331) participants were significantly higher than the very active participants $(5.025 \pm 2.259)(p<.05)$. Most of the moderate active participants $(64.67 \%)$ were at low risk of eating disorder and few were at high risk $(8.6 \%)$. The remaining $26.67 \%$ were very active participants who were at low risk of eating disorder. The distribution of the participants with respect to eating disorder risk categories was significant different for very active and moderate active categories $\left(\chi^{2}=23.715, p<.05\right)$. There was a significant difference of bulimia preoccupation between the physical activity of the participants (very active $=5.150 \pm 0.415$, moderate active $=4.335 \pm 0.697, p<.05$ ). The mean score for dieting and oral control was not significantly different between the two physical activity levels $(p>.05)$.

Table 1. Demographics of the participants

\begin{tabular}{|c|c|}
\hline Variables & $n(\%)$ \\
\hline \multicolumn{2}{|l|}{ Category of sports } \\
\hline Weight & $28(18.7)$ \\
\hline Non-weight & $122(81.3)$ \\
\hline \multicolumn{2}{|l|}{ Type of sports } \\
\hline Individual & $124(82.7)$ \\
\hline Team & $26(17.3)$ \\
\hline \multicolumn{2}{|l|}{ Age groups } \\
\hline$<12$ years old & $6(4)$ \\
\hline $13-15$ years old & $36(24)$ \\
\hline $16-18$ years old & $71(47.3)$ \\
\hline $19-21$ years old & $37(24.7)$ \\
\hline \multicolumn{2}{|l|}{ Years of experience } \\
\hline$<1$ year & $19(12.7)$ \\
\hline $1-3$ years & $39(26)$ \\
\hline $4-6$ years & $82(54.7)$ \\
\hline$>7$ years & $10(6.7)$ \\
\hline Height $(\mathrm{cm})$ & $\begin{array}{c}\operatorname{Min}=127, \operatorname{Max}=167(155.244 \\
\pm 9.482)\end{array}$ \\
\hline Weight (kg) & $\begin{array}{c}\operatorname{Min}=25.40, \operatorname{Max}=88.10 \\
(57.291 \pm 17.076)\end{array}$ \\
\hline Body fat $\%$ & $\begin{array}{c}\operatorname{Min}=12, \operatorname{Max}=42.40(28.716 \pm \\
8.248)\end{array}$ \\
\hline
\end{tabular}

The mean eating disorder score was $8.18 \pm 5.856$ with about $8.6 \%$ participants at high risk of eating disorders (Table 4). The high risks of eating disorders were participants from the non-weight sports category. The distribution of the participants with respect to eating disorder categories was significant different for weight and non-weight sports categories $\left(\chi^{2}=75.54, p<.05\right)$. There was a significant different of eating disorder between the weight sports $(5.00 \pm 2.568)$ and non-weight sports $(8.909 \pm 6.155)$ $(p<.05)$. Bulimia preoccupation also showed a significant different between

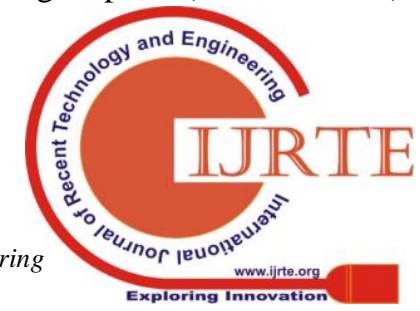


weight sports $(5.375 \pm 0.243)$ and non-weight sports (4.363 $\pm 0.662)(p<.05)$. However, dieting and oral control did not differ significantly by the categories $(p<.05)$.

Table 2. Comparison of the eating disorder and the subscales between physical activity

\begin{tabular}{|c|c|c|c|c|}
\hline Variables & $\begin{array}{c}\text { VA }(M \pm \\
\text { SD) } \\
(n=40)\end{array}$ & $\begin{array}{c}\text { MA }(M \pm \\
\text { SD) } \\
(\mathbf{n}=\mathbf{1 1 0})\end{array}$ & $\begin{array}{c}\text { Total (M } \\
\pm \mathrm{SD}) \\
(\mathrm{N}=150)\end{array}$ & p-value \\
\hline Eating disorder & $\begin{array}{c}5.025 \pm \\
2.259\end{array}$ & $\begin{array}{c}9.327 \pm \\
6.331\end{array}$ & $\begin{array}{l}8.18 \pm \\
5.856\end{array}$ & $.001 *$ \\
\hline $\begin{array}{l}\text { Low risk } \\
(\mathrm{n}(\%))\end{array}$ & 40 (26.67) & 97 (64.67) & $\begin{array}{c}137 \\
(91.4)\end{array}$ & $.001 *$ \\
\hline $\begin{array}{l}\text { High risk } \\
(\mathrm{n}(\%)) \\
\chi^{2} \text { value }= \\
64.145\end{array}$ & - & $13(8.6)$ & $13(8.6)$ & \\
\hline Dieting & $\begin{array}{c}4.842 \pm \\
0.226\end{array}$ & $\begin{array}{c}4.682 \pm \\
0.704\end{array}$ & $\begin{array}{c}4.725 \pm \\
0.617\end{array}$ & $.037 *$ \\
\hline $\begin{array}{l}\text { Bulimia } \\
\text { nervosa }\end{array}$ & $\begin{array}{c}5.783 \pm \\
0.278\end{array}$ & $\begin{array}{c}4.335 \pm \\
0.697\end{array}$ & $\begin{array}{c}5.373 \pm \\
0.462\end{array}$ & $.001 *$ \\
\hline $\begin{array}{c}\text { Food } \\
\text { preoccupation }\end{array}$ & $\begin{array}{c}4.958 \pm \\
0.454\end{array}$ & $\begin{array}{c}4.064 \pm \\
1.210\end{array}$ & $\begin{array}{c}4.302 \pm \\
1.133\end{array}$ & $.001 *$ \\
\hline Oral control & $\begin{array}{c}4.646 \pm \\
0.265\end{array}$ & $\begin{array}{c}4.638 \pm \\
1.554\end{array}$ & $\begin{array}{c}4.640 \pm \\
1.336\end{array}$ & .972 \\
\hline
\end{tabular}

Table 3. Comparison of the eating disorder and the subscales between weight and non-weight sports

\begin{tabular}{|c|c|c|c|c|}
\hline Variables & $\begin{array}{l}\text { Wgt (M } \\
\pm \text { SD) } \\
(n=28)\end{array}$ & $\begin{array}{l}\text { Non-Wgt } \\
(M \pm S D) \\
(n=122)\end{array}$ & $\begin{array}{l}\text { Total }(M \\
\pm \text { SD) } \\
(\mathbf{N}=150)\end{array}$ & p-value \\
\hline Eating disorder & $\begin{array}{l}5.00 \pm \\
2.568\end{array}$ & $\begin{array}{l}8.909 \pm \\
6.155\end{array}$ & $\begin{array}{l}8.18 \pm \\
5.856\end{array}$ & $.001 *$ \\
\hline $\begin{array}{l}\text { Low risk } \\
(\mathrm{n}(\%))\end{array}$ & $28(18.7)$ & 109 (72.7) & 137 (91.4) & $.001 *$ \\
\hline $\begin{array}{l}\text { High risk } \\
(\mathrm{n}(\%)) \\
\chi^{2} \text { value }=\end{array}$ & - & $13(8.6)$ & $13(8.6)$ & \\
\hline
\end{tabular}

75.54

\begin{tabular}{lllll} 
Dieting & $4.876 \pm$ & $4.690 \pm$ & $4.725 \pm$ & $.004^{*}$ \\
& 0.101 & 0.678 & 0.617 & \\
Bulimia & $5.905 \pm$ & $5.251 \pm$ & $5.373 \pm$ & $.001^{*}$ \\
& 0.153 & 0.421 & 0.462 & \\
Food & $5.060 \pm$ & $4.128 \pm$ & $4.302 \pm$ & $.001^{*}$ \\
preoccupation & 0.497 & 1.167 & 1.133 & \\
Oral control & $4.740 \pm$ & $4.617 \pm$ & $4.640 \pm$ & .369 \\
& 0.129 & 1.480 & 1.336 & \\
\multicolumn{4}{c}{ *significant level is at $.05(\mathrm{p}<.05)$} \\
Wgt = weight sports, Non-wgt = non-weight sports
\end{tabular}

In comparing the variables by age groups, there were significant different of eating disorder, dieting and bulimia preoccupation $(p<.05)$ (Table 5). There was a significant association between eating disorder and age groups of the respondents $\left(\chi^{2}=71.555, p<.05\right)$. Oral control did not has significant different between the age groups $(p>.05)$.

Table 4. Comparison of eating disorder and subscales by age groups

\begin{tabular}{|c|c|c|c|c|c|}
\hline & \multicolumn{5}{|c|}{ Age groups (years) $(\mathrm{M} \pm \mathrm{SD})$} \\
\hline Variables & $\begin{array}{l}<12 \\
(n=6)\end{array}$ & $\begin{array}{l}13-15 \\
(n=36)\end{array}$ & $\begin{array}{l}16-18 \\
(n=71)\end{array}$ & $\begin{array}{l}19-21 \\
(n=37)\end{array}$ & p-value \\
\hline $\begin{array}{l}\text { Eating } \\
\text { disorder }\end{array}$ & $\begin{array}{r}13.667 \\
\pm 9.811\end{array}$ & $\begin{array}{c}9.556 \pm \\
7.044\end{array}$ & $\begin{array}{c}9.366 \pm \\
4.602\end{array}$ & $\begin{array}{c}3.676 \pm \\
2.935\end{array}$ & $.001 *$ \\
\hline $\begin{array}{l}\text { Low risk } \\
(\mathrm{n}(\%))\end{array}$ & 2 & 27 & 71 & 37 & $.001 *$ \\
\hline $\begin{array}{l}\text { High risk } \\
(\mathrm{n}(\%)) \\
\chi^{2} \text { value }= \\
71.555\end{array}$ & 4 & 9 & - & - & \\
\hline Dieting & $\begin{array}{c}4.180 \pm \\
0.755\end{array}$ & $\begin{array}{c}4.643 \pm \\
0.613\end{array}$ & $\begin{array}{c}4.747 \pm \\
0.684\end{array}$ & $\begin{array}{c}4.725 \pm \\
0.617\end{array}$ & .073 \\
\hline $\begin{array}{l}\text { Bulimia } \\
\text { nervosa }\end{array}$ & $\begin{array}{c}5.778 \pm \\
0.172\end{array}$ & $\begin{array}{c}5.435 \pm \\
0.389\end{array}$ & $\begin{array}{c}5.291 \pm \\
0.481\end{array}$ & $\begin{array}{c}5.373 \pm \\
0.462\end{array}$ & .051 \\
\hline $\begin{array}{c}\text { Food } \\
\text { preoccupation }\end{array}$ & $\begin{array}{c}5.111 \pm \\
0.344\end{array}$ & $\begin{array}{c}4.667 \pm \\
1.005\end{array}$ & $\begin{array}{c}3.695 \pm \\
1.142\end{array}$ & $\begin{array}{c}4.302 \pm \\
1.133\end{array}$ & $.001 *$ \\
\hline Oral control & $\begin{array}{c}3.667 \pm \\
1.033\end{array}$ & $\begin{array}{c}4.560 \pm \\
1.679\end{array}$ & $\begin{array}{c}4.557 \pm \\
0.330\end{array}$ & $\begin{array}{c}4.640 \pm \\
1.336\end{array}$ & .076 \\
\hline
\end{tabular}

Table 5. Relationship between eating disorder and body fat percentage

\begin{tabular}{cc}
\hline Variable & r- value \\
\hline Eating disorder & $-.180 *$ \\
EAT subscales & \\
Dieting & -.017 \\
Bulimia nervosa & $-.212^{*}$ \\
Food preoccupation & $-.296^{*}$ \\
Oral control & $.209 *$ \\
$*$ correlation is significant at $.05(\mathrm{p}<.05)$ & \\
\hline
\end{tabular}

The eating behavior $(r=-.181)$ and bulimia preoccupation $(r=-.285)$ were found significant negative relationship with body fat percentage $(p<.05)$, while oral control was significant positive correlated $(r=.212)$. Dieting was found not significantly correlated with the body fat percentage $(p>$. 05) (Table 6).

\section{Discussion}

As overall, the athletes were at low risk of eating disorder. However, in comparing by physical activity and category of sports represented, the moderately active and non-weight sports athletes exhibited a high risk of eating disorder. The weight sports are sports which require athletes to compete for certain weight categories. There was strong evidence that eating disorder was more prominent in weight sports category ${ }^{3}$. However, there is a contrast finding in the present study where the high risk of eating disorder was among the non-weight sports athletes. As being found out that the moderately active and non-weight sports athletes

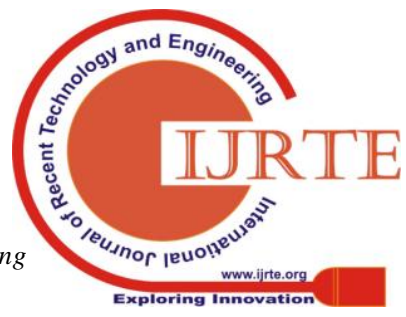


were both displayed a high risk of eating disorder, these two variables could link closely. The less active athletes tend to suffer eating disorder to avoid getting fat. In addition, young athletes' misconception that being thinner makes them a better athlete could increase the risk of developing an eating disorder. Currie3 supports this finding. The pursuit of sporting excellence could encourage these athletes to eat in wrong ways.

The younger athletes exhibited a great tendency for risk of eating disorder in the present study. Those who were less than 12 years old scored higher than others in the eating disorder. The scores were descending across the age groups; the older the athletes, the lower the eating disorder score. This could be related to the experience of the athletes in sports competition. The sports experience was less in the younger athletes, thus the exposure or knowledge on eating correctly were lacking. Specialization in one sport at an early age and sudden increases in training volume could be the reason of developing eating disorder ${ }^{16}$. This finding could be an alarm that risk of eating disorder is higher at younger age.

The lower the mean score the subscales, the greater the eating disorder. Dieting behavior was also prominent in the moderately active athletes and non-weight sports athletes as compared with their counterparts. Dieting is the behavior of concerning too much on the food intake quantities by avoiding high calorie food and a pre-occupation of being thinner. This finding alerts us that even though the requirement of the non-weight sports does not emphasize much on some weight categories to compete, the athletes might overthink on eating normally. Again, because of the fear of taking high calories from food, these athletes tend to practise dieting in their eating behavior. The present study was contradicted with previous study ${ }^{17}$ where they supported the statement that obsess neurotic action on diet is related to the commitment in extreme exercise or physical activity to burn-off the calories. However, dieting behavior did not showed a significant different across the age groups. The athletes are assumed to behave similarly towards food intake regardless of their age.

Interestingly, bulimia preoccupation was greater in moderately active athletes and in the non-weight sports athletes. As many people living with bulimia might have normal appearance, the non-weight sports do not actually need to compete in desire weight, but however they might end up having an unpleasant size. Based on the researchers' observation, the non-weight sports athletes were much bigger as compare to the weight sports athletes. Thus, this might develop the bulimic incident. As the moderately active athletes would have a lower metabolic equivalent, these adolescents were in the process of gaining height and weight due to puberty and it could stress this population to accept it and be in denial at the same time on the changes of their body. The conflict of sports acceptance that athletes must be thin and lean-looking forces them to practise unusual eating behavior. Again, they might think that fitness is related to thinness or such 'athletic' eating will improve performance ${ }^{3}$. Furthermore, it was reported that the adolescents would be more likely low in body weight management knowledge ${ }^{18}$, and the idea of 'athletics' eating might influence these athletes. The adolescents age of 21 years old and below is where the females will be at the condition where they had become fully grown and increased fat mass ${ }^{19}$, therefore, this could be one of the struggle to adapt to the changes in shape and size besides being athletes.

Food preoccupation was significant among all the independent variables measured. The moderately active athletes, non-weight sports athletes and age groups of 16 to 18 years old were assumed to put more significant concern on food. Unwarranted thoughts and actions on food content characterized a clinical eating disorder. Therefore, the athletes could have possibility of bulimia too ${ }^{17}$. As this group put so much thought on food intake and become more serious in their sports training, the fear of storing excess energy from eating normally might put the athletes at the episodes of binge and purge.

Oral control displayed to be not associated with physical activity level, sports category and age groups. It is the behavior resembles eating control and the perceived pressure from others to gain weight. Results indicated that the athletes reported greater score on food preoccupation than oral control, dieting and bulimia nervosa. Scores on food preoccupation were significant on all the independent variables measured, and therefore possibly influence the bulimia nervosa behavior.

In addition, there were significant relationships between eating disorder and the three subscales (bulimia nervosa, food preoccupation and oral control) with body fat percentage of the athletes. This was contradicted with similar study on Malaysian university students ${ }^{20}$. The relationship of eating disorder and body fat percentage was significantly negative. This indicates that the higher the eating disorder, the lower the body fat percentage and vice versa. This finding contrast with a similar study ${ }^{21}$ where they found out that body composition and eating disorder was positively correlated. The athletics make up of these adolescents make them exhibit a different finding. As the body fat percentage is high, the bulimia nervosa and food preoccupation were also greater as shown by the significant negative relationships. As reported, dieting practices were more likely among the heavier adolescents ${ }^{22}$ in this very study, the binge and purge and thought of foods were more significant in those with higher body fat percentage. For oral control, there was a contradicted relationship revealed. The oral control was positively correlated with the body fat percentage which indicated that, the athletes did not perceived pressure from others to gain weight and controlling of eating was lower even when their body fat percentage was high.

\section{Conclusion}

In conclusion, the moderately active athletes and non-weight sports athletes were more likely to have higher eating disorders. However, the oral control was not prominent issue. The strength of the relationships was small 
between some of the subscales and body fat percentage Thus, preventive action could be taken sooner before the athletes suffer severe eating disorder as they are going to be serious in professional sports career. Age groups also not associated with any of these eating disorders. It is recommended that coaches should alert on the less vigorous sports athletes and to the non-weight sports athletes on their eating behavior. Implementing program to improve knowledge of these athletes on healthy eating and eliminate the 'athletic' eating should be conducted so that the normal pattern of eating could be developed in the early age of sporting career.

\section{ACKNOWLEDGEMENTS}

The authors acknowledge the financial support from Dana Kecemerlangan (600-IRMI/PBT 5/3 (005/2018)), Universiti Teknologi MARA Kampus Samarahan, Sarawak, Malaysia. Special thanks to Sarawak Sports Corporation for the permission and coaches and the participants for all their support.

\section{REFERENCES}

[1] Shelton VL, Valkyrie KT. College student stress: a predictor of eating disorder precursor behaviors. The Alabama Counseling Association Journal. 2010;35(2):2.

[2] Krejcie RV, Morgan DW. Determining sample size for research acitvities. Educational and Psychological Measurement. 1970;30:607 10.

[3] Currie A. Sport and eating disorders-understanding and managing the risks. Journal of Sports Medicine. 2010;1(2):63-8

[4] Rodriguez-Cano T, Beato Fernandez I, Belmonte-Llario A. A new contributions to the prevalence of eating disorders in Spanish adolescents:detection of the false negative. Eur Psychiatry. 2005;20(2).

[5] IPH. National Health and Morbidity Survey 2015 (NHMS 2015). The Sport Journal Kuala Lumpur: Institute for Public Health, Ministry of Health 2015.

[6] Barbio N, Canals J, Pietrobelli A, Perez S, Arija V. A two-phase population study: relationships between overweight, body composition and risk of eating disorders. Nutrition Hospital 2009;24(4).

[7] Suarez GF, Vaz LF, Guisado J, Gomez LL. Study of eating habits in female population comparing groups with and without food related diseases. Nutrition Hospital 2003;18:5.

[8] Dev RDO, Permal V, Mohd Sofian O. Rural urban differences in body image perception, body mass index and dieting behaviour among Malay adolescents Malaysian schoolgirls. European Journal of Scientific Research. 2009;34(1):24.

[9] Yeger J, Devlin MJ, Halmi KA, Herzog DB, Mitchell III JE, Powers P, et al. Practice guideline for the treatment of patients with eating disorders 3ed: American Psychological Association; 2006.

[10] Khor GL, Zalilah MS, Pjan YY, Ang M, Maznah B, Norimah AK. Perceptions of body image among Malaysian male and female adolescents. Singapore Medical Journal. 2009;50:9.

[11] Norhayati M, Chin YS, Mohd Nasir MT, Zalilah MS, Chan YM, editors. Body image disturbance and disordered eating in overweight and obese male and female Malaysian adolescents. In combating obesity: societal and environmental issues and challenges. Malaysian Association for the Study of Obesity Scientific Conference 2015; Kuala Lumpur.

[12] Global Physical Activity Questionnaire: GPAQ version 2.0. Geneva: WHO [Internet]. World Health Organization (WHO). 2009.

[13] Soo KL, Zalilah MS, Mohd Nasir MT, Samah PA. Eating behavior, body image, and self-esteem of adolescents girls in Malaysia. Percept Mot Skills. 2008;106(2).

[14] Rivas T, Bersabe R, Jimenez M, Berrocal C. The eating attitude test (EAT-26) reliability and validity in Spanish female samples Spanish Journal Psychology. 2010;13(2).

[15] Garner DM, Garfinkel PE. The eating attitudes test: an index of the symptoms of anorexia nervosa. 1979;9:273-9.

[16] Sundgot-Borgen J. Risk and trigger factors for the development of eating disorders in female elite athletes. Med Sci Sports Exerc. 1994;26.

[17] Lane HJ, Lane AM, Matheson H. Validity of the eating attitude test among exercisers. Journal of Sports Science and Medicine. 2004;3:10.
[18] Pon LW, Kandiah M, Mohd Nasir MT. Body image perception, dietary practices and physical activity of overweight and normal weight Malaysian female adolescents. Malaysian Journal of Nutrition 2004;10(2):17.

[19] Vizmanos B, Marti-Henneberg C. Puberty begins with a characteristic subcutaneous body fat mass in each sex. Eur J Clin Nutr. 2000;54(3).

[20] Khor GL, Cobiac L, Skrzypiec G. Gender differences in eating behaviour and social self-concept among Malaysian university students Malaysian Journal of Nutrition 2002;8(1):24.

[21] Farah Wahida Z, Mohd Nasir MT, Hazizi AS. Physical activity, eating behavior and body image perception among young adolescents in Kuantan, Pahang. Malaysian Journal of Nutrition 2011;17(3):12.

[22] Story M, Stevens J, Evans M, Cornell CEJ, Gittelsohn J, Going SB, et al. Weight loss attempts and attitudes toward body size, eating and physical activity in American Indian children: relationship with weight status and gender. Obes Res. 2001;9:8.

\section{AUTHORS PROFILE}

my name is Patricia Pawa Pitil, i am working as Lecturer, Faculty of Sports Science \& Recreation, Universiti Teknologi MARA, Cawangan Sarawak, Kampus Samarahan, Jalan Meranek, 9.4300, Kota Samarahan, Malaysia. my area of research is sports science.

my name is Wan Juliana Emeih Wahed, i am working as Lecturer, Faculty of Art \& Design, Universiti Teknologi MARA, Cawangan Sarawak, Kampus Samarahan, Jalan Meranek, 94300, Kota Samarahan, Malaysia.my area of interest is fashion and art. 